Göran I. Ågren · Ernesto Bosatta · Alison H. Magill

\title{
Combining theory and experiment to understand effects of inorganic nitrogen on litter decomposition
}

Published online: 30 June 2001

(C) Springer-Verlag 2001

In the printed version of this paper [Oecologia (2001) 128: 94-98] there were a number of errors in the sentence following Eq. 2. The correct version should read as follows:

...where $q_{0}$ is the initial litter quality, $f_{\mathrm{c}}$ is carbon concentration in the decomposer biomass $\left(\mathrm{kg} \mathrm{C} \mathrm{kg}^{-1}\right.$ biomass), $\beta$ is a shape factor used to describe the relation between $q$ and decomposer growth rate (dimensionless), $\eta_{11}$ is a factor that describes the average change in quality when one substrate is transformed into another (dimensionless), and $u_{0}$ is the decomposer growth rate per unit of substrate carbon (year-1).

The online version of the original article can be found at http://dx.doi.org/10.1007/s004420100646

G.I. Ågren (国) E. B. Bosatta

Department of Ecology and Environmental Research,

Swedish University of Agricultural Sciences, P.O. Box 7072,

S-750 07 Uppsala, Sweden

e-mail: Goran.Agren@eom.slu.se

Tel.: +46-18-672449, Fax: +46-18-673430

A.H. Magill

Complex Systems Research Center,

University of New Hampshire, Durham, NH 03824, USA 